\title{
Embedded Immune-Evolutionary Programming for Economic Dispatch of Generators with Prohibited Operating Zones
}

\author{
N. S. Razali ${ }^{1}$, M. H. Mansor ${ }^{2}$, I. Musirin ${ }^{3}$, M. M. Othman ${ }^{4}$, M. Akoury ${ }^{5}$ \\ ${ }^{I}$ Department of Electrical Power Engineering, College of Engineering, Universiti Tenaga Nasional (UNITEN) Kajang, Malaysia \\ ${ }^{2}$ Department of Electrical Power Engineering, College of Engineering, Universiti Tenaga Nasional (UNITEN) Kajang, Malaysia \\ ${ }^{3}$ Faculty of Electrical Engineering Universiti Teknologi MARA (UiTM) Shah Alam, Selangor, Malaysia \\ ${ }^{4}$ Faculty of Electrical Engineering Universiti Teknologi MARA (UiTM) Shah Alam, Selangor, Malaysia \\ ${ }^{5}$ National Grid, Bearwood Rd, Sindlesham, Wokingham RG41 5BN, United Kingdom \\ *Corresponding author E-mail: mhelmi@uniten.edu.my
}

\begin{abstract}
Economic Dispatch (ED) is one of the popular power system problems. It is solved by the grid system operators (GSOs) to find the cheapest production cost for dispatching power from generations to the demands (loads). It is crucial to have cheap production cost and at the same time satisfying all system constraints such as generating units' operating limits, transmission lines capacity and spinning reserve. ED of generators with prohibited operating zones is considered as a nonconvex ED as it has inequality constraints that need to be considered. This inequality constraint is the operating limits of generating units that considering the allowable and prohibited operating zones. The generating units must be ensured, that they are only operated within the allowable limits to avoid problem with the equipments that related to them. Some generating units will experience high vibration at certain level of operating limits and will burn more fuel to maintain at certain level of load. This paper presents an embedded technique to solve ED of generators problem with prohibited operating zones. The cloning process of Artificial Immune System (AIS) is inserted into Evolutionary Programming (EP) algorithm to form a new technique termed as Embedded Immune-Evolutionary Programming (EIEP). The proposed embedded technique has been tested on the IEEE 26-Bus Reliability Test System (RTS) with three different conditions of load. Besides that the results produced by the embedded technique has been compared with two single techniques which are AIS and EP. It is found that, the results of ED of generators with prohibited operating zones produced by EIEP is better than the two single techniques in terms of low total production cost.
\end{abstract}

Keywords: Economic Dispatch; Embedded; Prohibited Operating Zones; Artificial Immune System; Evolutionary Programming.

\section{Introduction}

Economic Dispatch (ED) is a substantial optimization issue in the power system operation. The aim of ED is to reduce the operating cost of the total power generation output. The generating units' output is scheduled to comply with the required load demand at the lowest cost of operation while fulfilling system equality and inequality constraint. Moreover, the increasing complexity of power systems is due to the growth of the load demand, the usage of fossil fuels in thermal power plant also increases. Thus, there has been concern about the increase in fuel costs and gaseous emissions into the environment. Therefore, optimization is important to minimize gaseous emissions, minimize the total cost and managing the system stability and security constraint.

Several techniques have been carried out by researchers and electrical engineers to solve economic dispatch for the past ten years such as Simulated Annealing (SA) [1], Tabu Search (TS) [2], Differential Evolution (DE) [3], Genetic Algorithm (GA) [4], Artificial Immune System (AIS) [5], Evolutionary Programming (EP) [6] and Particle Swarm Optimization (PSO) [7]. Nevertheless, most of the techniques applied are single optimization techniques which have drawbacks such as premature optimization results, long computational time and also getting stuck in local optima. Therefore, this paper proposed an embedded optimization technique termed as Embedded Immune-Evolutionary Programming
(EIEP) to solve economic dispatch of generators with prohibited operating zones. An operator from Artificial Immune System (AIS) is inserted into the core optimizer of Evolutionary Programming (EP). The reason for this insertion is to ensure that these two techniques AIS and EP are complementing each other to produce better optimization results of ED. Prior to the implementation of embedded immune-evolutionary programming, ED with prohibited operating zones of the IEEE 26-Bus Reliability Test System (RTS) was solved using two single techniques AIS and EP for the purpose of comparison. It is found that the EIEP outperformed the two single techniques in terms of giving better total production cost.

\section{Economic Dispatch with Prohibited Operat- ing Zones Problem Formulation}

Economic dispatch of generators with prohibited operating zones has the objective function to minimise the total production cost defined by the total production cost which is expressed as a quadratic function as shown in the equation (1).

$C_{\text {total }}=\sum_{i=1}^{n} C_{i}\left(P_{i}\right)=\sum_{i=1}^{n_{g}} \alpha_{i}+\beta_{i} P_{i}+\gamma_{i} P_{i}^{2}$ 
Where $\alpha_{i}, \beta_{i}$ and $\gamma_{i}$ are the cost coefficients of the ith generating unit and are subjected to generating unit constraints.

The constraints to be considered while optimizing the objective function are the real power balance constraint and the generators operating limits with prohibited operating zones which are shown in equation (2) and equations (4)-(8) respectively:

$P_{\text {demand }}+P_{\text {loss }}=\sum_{i=1}^{n} P_{i}$

Kron's formula is used to calculate the total transmission loss shown in equation (3):

$P_{\text {loss }}=\sum_{i=1}^{n_{g}} \sum_{j=1}^{n_{g}} P_{i} B_{i j} P_{j}+\sum_{i=1}^{n_{g}} B_{0 i} P_{i}+B_{00}$

Where $B_{i j}, B_{0 i}$ and $B_{00}$ are the components loss coefficient matrix. The cost curve for economic dispatch with prohibited operating zones is discontinuous. The operating limits of generating units are split into various zones which contain permissible and prohibited operating zones.

The permissible operating zones are as follows:

$P_{i(\min )} \leq P_{i} \leq P_{i(1)}$

$P_{i(2)} \leq P_{i} \leq P_{i(3)}$

$P_{i(4)} \leq P_{i} \leq P_{i(\max )}$

The prohibited operating zones are as follows:

$$
\begin{aligned}
& P_{i(1)} \leq P_{i} \leq P_{i(2)} \\
& P_{i(3)} \leq P_{i} \leq P_{i(4)}
\end{aligned}
$$

Where $P_{i(2)}$ and $P_{i(4)}$ are the lower bounds of the ith generating unit and $P_{i(1)}$ and $P_{i(3)}$ are the upper bounds of the ith generating unit.

From equations (4)-(8), it can be seen that the constraint of generating units' operating zones is nonconvex which have been derived from the input-output characteristics of generating units with prohibited operating zones shown in Figure 1.

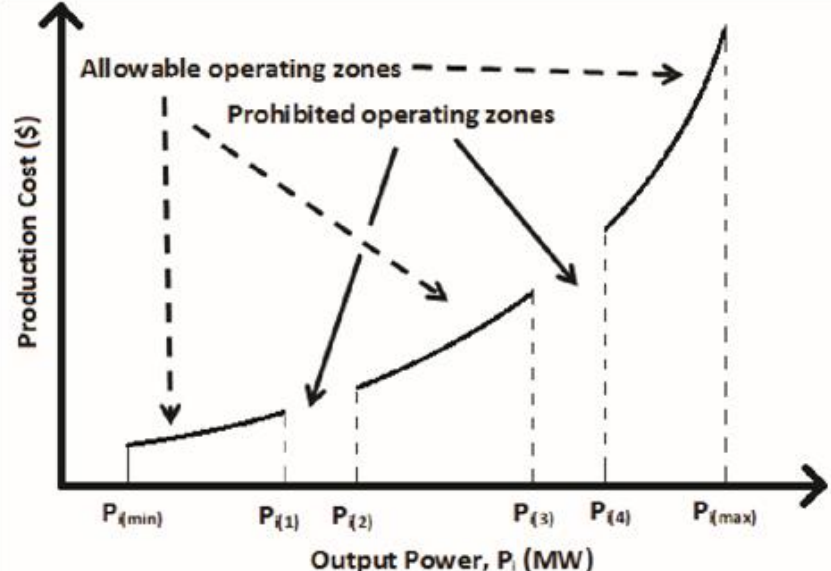

Fig. 1: The input - output characteristics of generating units with prohibit ed operating zones

\section{Implementation of Embedded Immune- Evolutionary Programming Algorithm for ED of Generators with Prohibited Operat- ing Zones}

As mentioned in introduction, an operator in AIS algorithm is inserted into the main optimizer of EP which is cloning process. This insertion will make the main optimizer to have additional one process. The cloning process will increase the chances of the initial population of control variables to be selected for the optimal solution of ED problem. The implementation process of the proposed embedded immune-evolutionary programming algorithm to solve economic dispatch of generators with prohibited operating zones is presented in Figure 2.
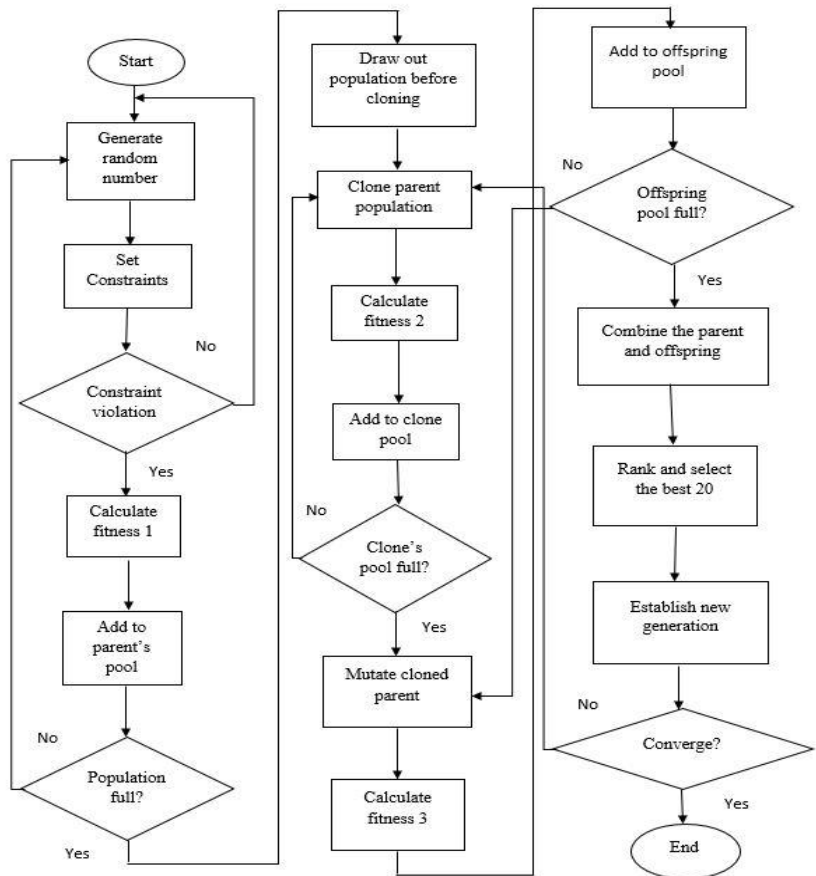

Fig. 2: Overall process of the EIEP for ED of generators with prohibited operating zones.

The steps of the proposed EIEP for solving ED with prohibited operating zones are explained in details as follows:

Step 1 - Initialization:

Initialization is a process of generating random numbers of control variables that optimize the objective function. The random numbers are generated according to the system constraints which are the real power balance and generators operating limits with prohibited operating zones. The size of population for each control variable is set to be twenty individuals. After that, the randomly generated control variables are used to evaluate the fitness of total production cost

Step 2 - Fitness 1 calculation:

Fitness 1 is the total production cost which is calculated using equation (1). based on the generators' operating costs. Twenty individuals of control variables and fitness 1 are added into parent's pool.

Step 3 - Cloning Process:

Each control variable of the parent population is cloned by a multiplier which is set to be 10 . The cloned population will then become 200 individuals.

Step 4 - Fitness 2 calculation:

Again the fitness of total production cost is calculated using the cloned individuals of control variables. The cloned parent population and fitness 2 are then added into clone's pool.

Step 5 - Mutation: 
Mutation is a process to transform the cloned parent's population to offspring population. These offspring are generated based on the art of Gaussian mutation technique. The Gaussian

$x_{i+m, j}=x_{i, j}+N\left(0, \beta\left(x_{\text {jmax }}-x_{\text {jmin }}\right)\left(\frac{f_{i}}{f_{\text {max }}}\right)\right)$

Where:

$x_{i+m, j}$ is mutated cloned parent (offspring),

$x_{i j}$ is parents,

$\beta$ is mutation scale, $0<\beta<1$,

$x_{\text {jmax }}$ is maximum random number for every control variable,

$x_{\text {jmin }}$ is minimum random number for every control variable,

$f_{i}$ is fitness for $i t h$ random number, and

$f_{\text {max }}$ is maximum fitness

Step 6 - Fitness 3 calculation:

For the third time, the fitness of total production cost is calculated using the mutated individuals of control variables. The mutated population and fitness 3 are added into offspring's pool.

Step 7 -Combination:

The cloned parent and offspring are combined together in one matrix to make a total number of 400 individuals. The number of rows of the matrix will become double.

Step 8 - Rank and selection:

The selection technique is to sort the combined population in ascending order based on the fitness values. The twenty fittest individuals which have the most minimum total production cost will be selected. The selected population is then considered for the next generation in the next evolution process.

Step 9-Convergence test:

Convergence test is done to decide whether the EIEP algorithm can achieve the optimum solution based on the stopping criterion [2]. It can be said to be converged when the difference between the 1st and 20th fittest individuals is 0.00001 . Otherwise, the process will repeat Step 3 until it converges.

\section{Results and Discussion}

The EIEP for ED with prohibited operating zones has been tested on the of the IEEE 26-Bus Reliability Test System (RTS). Prior to that, ED with prohibited operating zones for the bus system has been solved using the single optimization techniques AIS and EP. The 26-Bus system has six generating units which are located at buses $1,2,3,4,5$ and 26 .

The generating units' operating limits with prohibited operating zones and their cost coefficients are shown in Table 1. The production cost function of each generating unit is shown in Table 2. The unit for the production cost and generating unit's output are in $\$ / \mathrm{hr}$ and MW respectively.
The proposed EIEP for solving ED of generators with prohibited operating zones were tested with three different load conditions which are Condition 1 (No load increment), Condition 2 (50\% load increment) and Condition 3 (100\% load increment). By introducing these conditions, the performance of the proposed technique can be further assessed. Table 3 shows the results. The results of ED with prohibited operating zones are shown in Table 3, Table 4 and Table 5 respectively.

It can be seen from the three tables that EIEP gives better results in terms of lowest production cost which are $7479.90 \$ / \mathrm{h}, 7602.60$ $\$ / \mathrm{h}$, and $9733.80 \$ / \mathrm{h}$. From Table 1 , it can be seen that EIEP forced generating unit 1 less compared to the other two techniques which is only 59.84 MW. While for Condition 2 in Table 4, EIEP forced generating unit 2 more compared to the other techniques. This shows that generating unit 2 is cheaper than other units in the system for that particular demand (load). For Condition 3 which the load is increased $100 \%$, it can be seen that generating unit 26 produced the least power compared to other units for EIEP technique while generating unit 2 produced the least power for the other two techniques. It is known that the total production cost will increase as the demand (load) increases.

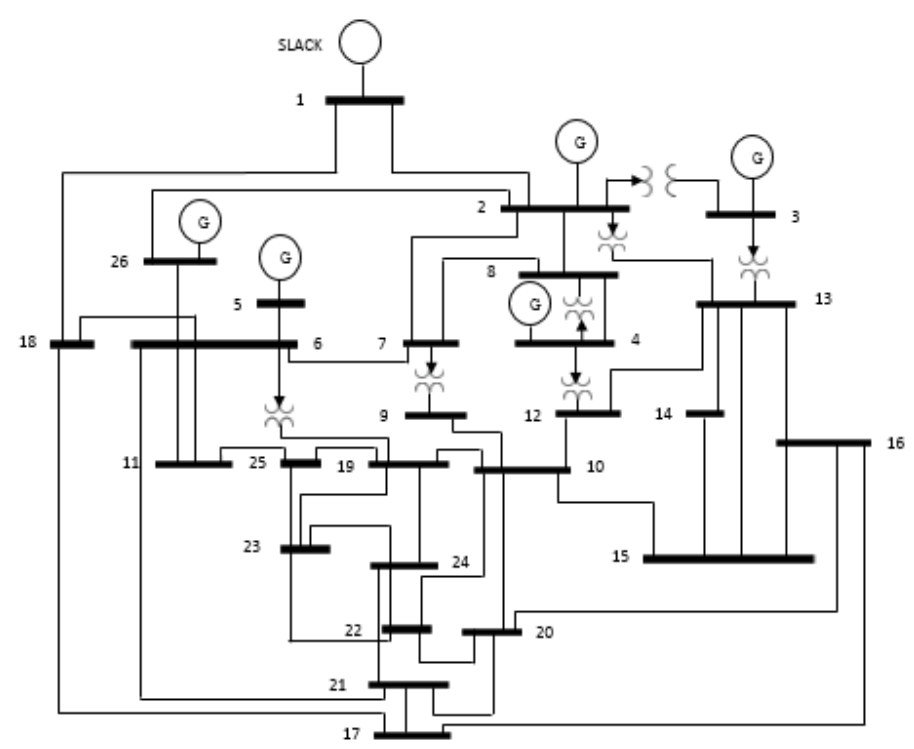

Fig. 3: The IEEE 26-Bus Reliability Test System (RTS)

Table 2: Generating units' production cost function of IEEE 26-Bus

\begin{tabular}{|c|l|}
\hline Generator no. & Cost function \\
\hline 1 & $C_{1}=240+7.0 P_{1}+0.0070 P_{1}^{2}$ \\
\hline 2 & $C_{2}=200+10.0 P_{2}+0.0095 P_{2}^{2}$ \\
\hline 3 & $C_{3}=220+8.5 P_{3}+0.0090 P_{3}^{2}$ \\
\hline 4 & $C_{4}=200+11.0 P_{4}+0.0090 P_{4}^{2}$ \\
\hline 5 & $C_{5}=220+10.5 P_{5}+0.0080 P_{5}^{2}$ \\
\hline 26 & $C_{26}=190+12.0 P_{26}+0.0075 P_{26}^{2}$ \\
\hline
\end{tabular}

Table 1: IEEE 26-Bus RTS operating limits with prohibited operating zones and their cost coefficients

\begin{tabular}{|c|c|c|c|c|c|c|}
\hline Generator no. & Gen. 1 & Gen. 2 & Gen. 3 & Gen. 4 & Gen. 5 & Gen. 26 \\
\hline $\begin{array}{l}P_{\max } \\
(\mathbf{M W})\end{array}$ & 500 & 200 & 300 & 150 & 200 & 120 \\
\hline $\begin{array}{c}P_{\min } \\
(\mathbf{M W})\end{array}$ & 100 & 50 & 80 & 50 & 50 & 50 \\
\hline $\begin{array}{c}\alpha \\
\left(\$ / M M^{2} h r\right) \\
\end{array}$ & 0.007 & 0.0095 & 0.009 & 0.008 & 0.008 & 0.0075 \\
\hline $\begin{array}{c}\boldsymbol{\beta} \\
\left(\$ / \mathbf{M} M^{2} h r\right)\end{array}$ & 7 & 10 & 8.5 & 11 & 12 & 12 \\
\hline $\begin{array}{c}\gamma \\
(\$ / h r)\end{array}$ & 240 & 200 & 220 & 200 & 220 & 190 \\
\hline \multicolumn{7}{|c|}{ Prohibited operating zone (MW) } \\
\hline Zone 1 & $210-240$ & $90-110$ & $150-170$ & $80-90$ & $90-110$ & $75-85$ \\
\hline Zone 2 & $350-380$ & $140-160$ & $210-240$ & $110-120$ & $140-150$ & $100-105$ \\
\hline
\end{tabular}


Table 3: Results of ED with prohibited operating zones obtained using AIS, EP and EIEP for Condition 1

\begin{tabular}{|l|l|l|l|l|l|l|l|}
\hline \multirow{2}{*}{$\begin{array}{l}\text { Optimization tech- } \\
\text { nique }\end{array}$} & \multicolumn{6}{|l|}{ Generating units output (MW) } & \multicolumn{2}{l|}{$\begin{array}{l}\text { Total production } \\
\text { cost } \mathbf{( \$ / h )}\end{array}$} \\
\hline AIS & $\mathbf{P}_{\mathbf{g} 1}$ & $\mathbf{P}_{\mathbf{g} 2}$ & $\mathbf{P}_{\mathbf{g} 3}$ & $\mathbf{P}_{\mathbf{g} 4}$ & $\mathbf{P}_{\mathbf{g} 5}$ & $\mathbf{P}_{\mathbf{g} 26}$ \\
\hline EP & 111.34 & 185.25 & 173.83 & 31.30 & 192.12 & 59.18 \\
\hline EIEP & 150.53 & 137.70 & 143.57 & 30.70 & 158.89 & 60.27 \\
\hline
\end{tabular}

Table 4: Results of ED with prohibited operating zones obtained using AIS, EP and EIEP for Condition 2

\begin{tabular}{|c|c|c|c|c|c|c|c|}
\hline \multirow{2}{*}{$\begin{array}{l}\text { Optimization tech- } \\
\text { nique }\end{array}$} & \multicolumn{6}{|c|}{ Generating units output (MW) } & \multirow{2}{*}{$\begin{array}{l}\text { Total production } \\
\text { cost }(\$ / h)\end{array}$} \\
\hline & $\mathbf{P}_{\mathrm{g} 1}$ & $\mathbf{P}_{\mathrm{g} 2}$ & $\mathbf{P}_{\mathrm{g} 3}$ & $\mathbf{P}_{\mathrm{g} 4}$ & $\mathbf{P}_{\mathrm{g} 5}$ & $\mathbf{P}_{\mathrm{g} 26}$ & \\
\hline AIS & 171.33 & 73.06 & 205.76 & 130.24 & 54.96 & 87.41 & 8878.80 \\
\hline EP & 291.08 & 85.66 & 140.47 & 63.89 & 74.97 & 112.83 & 9219.70 \\
\hline EIEP & 157.56 & 174.52 & 80.01 & 83.66 & 51.18 & 50.05 & 7602.60 \\
\hline
\end{tabular}

Table 5: Results of ED with prohibited operating zones obtained using AIS, EP and EIEP for Condition 3

\begin{tabular}{|c|c|c|c|c|c|c|c|}
\hline \multirow{2}{*}{$\begin{array}{l}\text { Optimization tech- } \\
\text { nique }\end{array}$} & \multicolumn{6}{|c|}{ Generating units output (MW) } & \multirow{2}{*}{$\begin{array}{l}\text { Total production } \\
\text { cost }(\$ / h)\end{array}$} \\
\hline & $\mathbf{P}_{\mathrm{g} 1}$ & $\mathbf{P}_{\mathrm{g} 2}$ & $\mathbf{P}_{\mathrm{g} 3}$ & $\mathbf{P}_{\mathrm{g} 4}$ & $\mathbf{P}_{\mathrm{g} 5}$ & $\mathbf{P}_{\mathrm{g} 26}$ & \\
\hline AIS & 120.29 & 161.87 & 196.53 & 141.26 & 162.63 & 99.17 & 11015.70 \\
\hline EP & 109.54 & 54.50 & 274.96 & 138.63 & 186.98 & 88.32 & 10770.90 \\
\hline EIEP & 147.97 & 112.09 & 140.75 & 149.51 & 183.22 & 50.22 & 9733.80 \\
\hline
\end{tabular}

\section{Conclusion}

The EIEP for solving ED problem with prohibited operating zones has been presented in this paper. Three conditions of load have been introduced to study the performance of the proposed technique. Furthermore, the proposed embedded technique has been compared with two single optimization techniques: AIS and EP. From the results produced by the three techniques, it can be concluded that EIEP is the best technique to solve ED of generators problem with prohibited operating zones. The cloning process of AIS that inserted into the core EP program plays an important role to increase the chances of the EIEP algorithm to find the best optimal solution of ED with prohibited operating zones.

\section{Acknowledgement}

The authors would like to acknowledge the Universiti Tenaga Nasional (UNITEN) for the financial support of this project. This research is supported by UNITEN under the UNITEN Internal Research Grant (UNIIG2018) with project code: J510050629.

\section{References}

[1] M. R. Avinaash, G. R. Kumar, K. A. Bhargav, T. S. Prabhu, and D. I. Reddy, "Simulated annealing approach to solution of multiobjective optimal economic dispatch," Intell. Syst. Control (ISCO), 2013 7th Int. Conf., no. 4, pp. 127-132, 2013.

[2] Sarjiya, A. B. Mulyawan, A. Setiawan, and A. Sudiarso, "Thermal unit commitment solution using genetic algorithm combined with the principle of tabu search and priority list method," Proc. - 2013 Int. Conf. Inf. Technol. Electr. Eng. "Intelligent Green Technol. Sustain. Dev. ICITEE 2013, pp. 414-419, 2013.

[3] W. A. Augusteen, R. Kumari, and R. Rengaraj, "Economic and various emission dispatch using differential evolution algorithm," 2016 3rd Int. Conf. Electr. Energy Syst. ICEES 2016, no. X, pp. 74-78, 2016.

[4] H. Mori and T. Horiguchi, "A genetic algorithm based approach to economic load dispatching," in [1993] Proceedings of the Second International Forum on Applications of Neural Networks to Power Systems, 1993, pp. 145-150.

[5] M. Basu, "Artificial immune system for dynamic economic dispatch,” Int. J. Electr. Power Energy Syst., vol. 33, no. 1, pp. 131-136, 2011.

[6] M. H. Mansor, M. R. Irving, and G. A. Taylor, "A decomposition/aggregation method for solving electrical power dispatch problems," in 2012 47th International Universities Power Engineering Conference (UPEC), 2012, pp. 1-7.

[7] N. M. Jamain, I. Musirin, M. H. Mansor, M. M. Othman, and S. A. M. Saleh, "Adaptive Particle Swarm Optimization for Solving NonConvex Economic Dispatch Problems," Pertanika J. Sci. Technol., vol. 25, no. (S) Mar, pp. 275-286, 2017. 